\title{
Oil Prices and the Impact of the Financial Crisis of 2007-2009
}

Anastasios G. Malliaris

Loyola University Chicago, tmallia@luc.edu

Ramaprasad Bhar

The University of New South Wales

Follow this and additional works at: https://ecommons.luc.edu/business_facpubs

Part of the Business Commons

\section{Author Manuscript}

This is a pre-publication author manuscript of the final, published article.

\section{Recommended Citation}

Malliaris, Anastasios G. and Bhar, Ramaprasad. Oil Prices and the Impact of the Financial Crisis of 2007-2009. Energy Economics, 33, 6: 1049-1054, 2011. Retrieved from Loyola eCommons, School of Business: Faculty Publications and Other Works, http://dx.doi.org/10.1016/j.eneco.2011.01.016

This Article is brought to you for free and open access by the Faculty Publications and Other Works by Department at Loyola eCommons. It has been accepted for inclusion in School of Business: Faculty Publications and Other Works by an authorized administrator of Loyola eCommons. For more information, please contact ecommons@luc.edu.

\section{(c) (†) $\ominus$}

This work is licensed under a Creative Commons Attribution-Noncommercial-No Derivative Works 3.0 License. (C) Elsevier B.V. 2011 


\title{
OIL PRICES AND THE IMPACT OF THE FINANCIAL CRISIS OF 2007-2009
}

\author{
Ramaprasad Bhar \\ School of Banking and Finance \\ The University of New South Wales \\ E-mail: $\underline{\text { R.Bhar@unsw.edu.au }}$ \\ A. G. Malliaris \\ Department of Economics and Finance \\ School of Business Administration \\ Loyola University of Chicago \\ E-mail: tmallia@luc.edu
}

\begin{abstract}
Oil prices increased dramatically during 2004-6. Industry experts initially attributed these price increases to fundamental factors such as the rise in global demand, but also because of disruptions in the supply of oil. The price increases however were so substantial that additional factors are needed to explain such dramatic changes. We propose that the decline in the value of the U.S. dollar measured both by the appreciation of the Euro and of gold prices, played an important role as oil suppliers demanded compensation for the declining value of the dollar. Using a Markov switching regime methodology we find evidence that this hypothesis is true prior to the financial crisis, but its validity does not hold after the crisis when oil prices crashed and the dollar rallied.
\end{abstract}

Key Words: Oil prices, Euro, Gold, Time series analysis, Markov switching regimes;

JEL Classification: C22, E44, G12

Current Version: December 28, 2010. Accepted for publication in ENERGY ECONOMICS, forthcoming 2011. 


\section{OIL PRICES AND THE IMPACT OF THE FINANCIAL CRISIS OF 2007-2009}

\section{Introduction}

Oil prices during 2004-6 increased dramatically. Oil experts initially attributed these increases to fundamental factors that contributed to an increase in global demand, particularly due to significant increase in world oil demand. In addition to increases in global demand, there were also disruptions in the supply of oil, partially due to the depreciation of the dollar nominal effective exchange rate and increases in the dollar

price of gold. The price increases however were so substantial that could not be explained only by fundamentals. So, additional factors are needed to clarify such dramatic changes. It is also interesting to note the role of monetary policy and low interest rates and speculation in firing up oil prices. The crash of oil prices in 2008Q4 was due to rapid deleveraging by speculative funds, rapid closing of oil positions, and drying up of liquidity.

We propose that the decline in the value of the U.S. dollar measured partially by the appreciation of the Euro and partially by increases in the price of gold played an important role as oil suppliers demanded compensation for the declining value of the dollar and prospects of global inflation. We find evidence that this hypothesis is true but its validity does not hold since the development of the global financial crisis that reversed the decline in the dollar and caused a crash in oil prices.

\section{Review of the literature}


The demand for oil is relatively inelastic so increases or decreases in the global quantity demanded are driven primarily by changes in global income. Over the past few decades and most recently, Hamilton (2009) argues that historical price shocks were primarily caused by significant disruptions in crude oil production that were brought about by largely exogenous geopolitical events such as the Iranian revolution in the fall of 1978, Iraq's invasion of Iran in September 1980, and Iraq's invasion of Kuwait in August 1990. During the period from 1973 until 2007, these three major events resulted in the disruption of the flow of oil from key global producers and as a result there was an increase in the price of oil.

From 2005 to 2007 the production of oil failed to increase and the decline in Saudi production was certainly one important factor contributing to flat world oil production during this period. The most important world oil exporter has for many years been Saudi Arabia. The volatility in the production of oil is not because of depletion but because the Saudis have followed a deliberate strategy of adjusting production in an effort to stabilize prices. On the other hand, global demand has been growing steadily. In developed countries, the demand for oil follows income growth that is around 3\%. In developing nations such as India and China where incomes grow much faster, around $10 \%$, the demand for oil has increased much faster.

Even though China was consuming more oil, some other countries such as the U.S. and Japan were consuming less. With world real GDP growing rapidly during 200607, the decrease in consumption in some countries can be attributed to an increase in price sufficient to reduce consumption in the OECD countries.

Considering that the income elasticity of petroleum demand in countries like the U.S. is about 0.5 , whereas in the newly industrialized countries it may be above unity, it is plausible to attribute the $6 \%$ increase in oil consumption between 2003 and 2005 to a shift in the demand curve caused by the increased global GDP.

Michael Masters, manager of a private financial fund who has been invited a number of times to testify before the United States Senate, argues that investors who bought oil not as a commodity to use but instead as a financial asset are responsible for the oil price spike of 2007-2008. He argues that this "financialization" of commodities introduced a speculative bubble in the price of oil. 
Oil prices started rising in the U.S. in early 2002 and continued their climb from a low of $\$ 30$ per barrel in 2002 to a high of around $\$ 150$ by mid-2008. The principle reason that Americans ignored the earlier price increase would seem to be because they could afford to do so. However, as the financial crisis of 2007-09 increased uncertainty and pushed the economy into a recession in December 2007, Americans decreased their demand for oil and oil prices crashed. From a high price of $\$ 150$ per barrel of oil in mid2008 , the price crashed back to around $\$ 30$ by the end of 2008. Although gasoline prices were likely a key factor behind plunging sales for U.S. automakers in the first half of 2008, falling income appear to be the biggest factor.

While oil is a commodity that plays a critical role in the global economy, the price of both gold and the Euro had very similar price patterns to oil. For example, since the early introduction of the Euro in 1999 (and notes and coins in 2002), it initially weakened against the dollar and subsequently it strengthened with very high correlation with the price of oil during the 2005-2007 period. Similarly, gold prices have been moving in direction similar to oil.

Krichene (2007) studied the dynamics of oil prices during January 2, 2002-July 7, 2006. Main findings were that these dynamics were dominated by frequent jumps, causing oil markets to be constantly out-of-equilibrium. While oil prices attempted to retreat following major upward jumps, there was a strong positive drift which kept pushing these prices upward. Volatility was high, making oil prices very sensitive to small shocks and to news. Krichene (2007) also extends his study of oil price dynamics by analyzing market expectations regarding future developments in these prices. Based on a sample of call and put option prices, he computes the implied risk-neutral distribution and finds it to be right-skewed, indicating that market participants maintained higher probabilities for prices to rise above the expected mean, given by the futures price. The risk-neutral distribution was also characterized by high volatility and high kurtosis, indicating that market participants were expecting prices to remain highly volatile and dominated by frequent jumps.

Oil prices may be correlated with other commodity prices such as agricultural, (wheat, corn, soybeans), energy (natural gas, gasoline, heating oil), metals (gold, silver, copper, palladium) and softs (cotton, coffee, lumber and sugar) jut to mention few. All of 
these are influenced by common macroeconomic factors such as interest rates, personal income, industrial production, exchange rates, and inflation. Moreover, some commodities are related in the sense that they are complements (e.g., silver and copper) or substitutes in consumption (e.g., gold and silver), and inputs in the production of others (e.g., oil, silver, and copper). We decided to choose gold for our study. Gold is most sensitive to inflation expectations and this is the variable that is relevant in our search for explanatory variables for the behavior of oil prices. Commodities such as corn, soybeans, sugar, copper and others may have complex dynamics in relation to oil with no straightforward co-movements. If inflation rises, one would expect most commodities to also increase and in such a case gold can serve as a satisfactory proxy.

Increases in commodity prices usually fuel expectations of higher inflation. If these increases cannot be explained by fundamentals alone, then monetary policy may view such increases as a signal of inflationary expectations. Assuming Central banks target inflation, increasing Fed funds rates may follow an increase in inflationary expectations. Market participants may respond to inflationary expectations by increasing the demand for gold and therefore its price and selling the currency and thus depreciating it; or if the Central banks respond to such inflationary expectations vigorously, the opposite may occur, with the price of gold dropping and the value of the currency appreciating. Employing the price of gold as a proxy for inflation in our model allows us to explain the behavior of oil in terms of inflationary expectations.

Oil is traded globally in U.S. dollars. The role of the U.S. dollar exchange rate has become very prominent in affecting and being affected by the price of oil. The Organization of the Petroleum Exporting Countries (OPEC) sets ${ }^{1}$ the price of oil in U.S. dollars by taking into account several factors such as the global fundamentals of world demand, the growth of the global economy, the strength of the U.S. dollar as measured in terms of other currencies, among them the Euro, the Japanese yen the British pound, the Swiss franc, the Chinese yuan and others. The OPEC then considers the appropriate global supply to the extent that it can to set a stable price. Increased oil prices to

\footnotetext{
${ }^{1}$ The OPEC no longer sets oil prices. It sets only quotas for its members. Oil prices are now determined in futures markets. Oil companies use these prices as reference price for their contracts with traditional customers. (This was suggested by a reviewer).
} 
compensate for the falling purchasing power of their dollar-denominated oil revenues is an important factor considered in setting the cartel price for the supply of oil.

Hammoudeh, Sari and Ewing (2009) found that prices of oil and silver and the exchange rate can send monetary authorities signals on the future direction of short-term interest rates as defined by the U.S. T-bill rate. Increases in oil and silver prices along with an appreciation of the U.S. dollar against the major currencies, provided this influx occurs concurrently, is a signal for tightening monetary policy.

Of course, this argument can go in the opposite direction. More specifically, if the Central bank is concerned about deflationary pressures during an economic recession when both the price of oil and gold are relatively low, then the Central bank may follow an easy monetary policy and further reduce the Fed funds rate to stimulate spending and prevent deflation. When markets assess that deflation has been prevented and that the economy is returning back to solid economic expansion, oil, gold and other commodity prices may rise in anticipation of such economic recovery. This scenario describes the economic conditions in the U.S. during the 2000-2002 period. First, the bursting of the NASDAQ bubble and the terrorists' attacks of September 11, 2001 pushed the U.S. economy into a recession during most of 2001. The Fed followed an easy monetary policy and it continued to do so up until 2004 because it had remained unsure about the progress of economic recovery. This extended period of easy monetary policy fueled the increases in housing prices and also the subsequent increases in oil, gold and other commodities.

Increases in the price of gold may cause depreciation in the U.S. dollar against the major currencies as traders sell the U.S. currency and buy gold. If on the other hand, monetary policy becomes tight to fight potential inflation and the Fed increases interest rates, then traders will sell gold and buy dollars. The results of Hammoudeh, Sari and Ewing (2009) also indicate that investors and the central bank should give the price of gold a higher weight in making decisions. Thus, the monetary authority and investors should focus more on the price of gold in such a case to obtain clues on the future direction of central bank policies and the behavior of the dollar vis-à-vis the other major currencies. Motivated by their findings we use the price of gold in our list of important explanatory variables. 
Furthermore, in terms of portfolio diversifications, Hammoudeh, Sari and Ewing (2009) found that, portfolio managers should include gold and silver as assets to a portfolio that also includes oil and copper or use hedges based on those non-precious commodities. Their results complement those of Ciner (2001) who considers gold and silver as substitutes to hedge certain types of risk. Thus, oil traders should get their signals from both fundamentals of world supply and demand but also from the actions of central banks that channel their interest rate policies through credit markets that have linkages with many sectors of the economy and translate both in real growth and inflationary expectations.

These observations lead us to formulating the following hypotheses.

\section{Hypotheses}

We use daily data for oil prices, gold prices, and the price of Euro in dollars, daily S\&P 500 Index, VIX (CBOE Volatility Index), and a measure of market liquidity provided the difference between the 3-month US Treasury bill (T-Bill rate) and the 3-month Euro dollar interest rate, usually called the TED spread. The TED spread measures baseline perceptions of global financial risk, as it is the difference between the risk free proxy and large interbank lending interest rates. The data start on 01/02/04 and ends on 04/16/09 for a total of 1327 observations.

We first hypothesize that the price of oil cannot be modeled by the standard regression methodology because the period includes subsets of times of very high volatility due to the financial crisis of 2007-09. Instead we propose a Markov switching regime methodology that endogenously identifies changes in the volatility and estimates three regressions that optimally fit the sample. Our hypothesis claims that during the sample period of January 2, 2004 to April 16, 2009, there were periods of varying volatility from low to very high and one would expect different explanatory variables to be significant during different regimes. During the low volatility regime, oil prices were very stable. Such stability also reflected stability in oil supply and demand fundamentals. When oil prices started increasing, driven by the global economic prosperity, we also observed a climbing of the: S\&P 500 Index prices, Euro prices and gold prices. During 
the same regime VIX signaled reduced volatility and a willingness among traders to assume more risk. The stable and intermediate volatility regimes were followed by very high volatility when oil prices crashed and this third regime is described by declining oil prices due to the financial crisis with: very high VIX, low liquidity, a declining Euro and correcting gold prices.

\section{Modeling and testing}

As part of an initial investigation in the massive changes in oil prices over the sample period we estimate the following linear relationship with a time varying conditional variance specification. We find all these variables are non-stationary in their levels using Augmented Dickey-Fuller tests as well as Phillip-Perron tests. These tests are carried out in the standard econometric software EViews. We, therefore carry out our investigation using first differences of the logarithms of the variables. The linear relation estimated is given by:

$$
\begin{aligned}
\Delta \text { Oil }_{\mathrm{t}}= & \alpha_{0}+\alpha_{1} \Delta \text { Oil }_{\mathrm{t}-1}+\alpha_{2} \Delta \operatorname{Gold}_{\mathrm{t}}+\alpha_{3} \Delta \text { Gold } \alpha_{4} \Delta \mathrm{SP}_{\mathrm{t}}+\alpha_{5} \Delta \mathrm{SP}_{\mathrm{t}-1}+ \\
& \alpha_{6} \Delta \operatorname{Eur}_{\mathrm{t}}+\alpha_{7} \Delta \operatorname{Eur}_{\mathrm{t}-1}+\alpha_{8} \Delta \operatorname{Vix}_{\mathrm{t}}+\alpha_{9} \Delta \operatorname{Vix}_{\mathrm{t}-1}+\alpha_{10} \Delta \operatorname{Ted}_{\mathrm{t}}+\alpha_{11} \Delta \operatorname{Ted}_{\mathrm{t}-1}+\varepsilon_{\mathrm{t}}
\end{aligned} .
$$

The variance of the residual, $\sigma_{t}^{2}$, is given a $\operatorname{GARCH}(1,1)$ structure given by:

$$
\sigma_{t}^{2}=\beta_{0}+\beta_{1} \varepsilon_{t-1}^{2}+\beta_{2} \sigma_{t-1}^{2}
$$




\section{Table 1}

Estimates of Linear Regression Relation with GARCH Variance

\begin{tabular}{|c|c|c|c|c|c|c|c|}
\hline \multicolumn{8}{|c|}{ Mean equation: } \\
\hline$\alpha_{0}$ & $\alpha_{1}$ & $\alpha_{2}$ & $\alpha_{3}$ & $\alpha_{4}$ & $\alpha_{5}$ & $\alpha_{6}$ & $\alpha_{7}$ \\
\hline $\begin{array}{c}0.0010^{* *} \\
(1.98)\end{array}$ & $\begin{array}{c}-0.0556^{* * * *} \\
(-1.88)\end{array}$ & $\begin{array}{l}0.6022^{*} \\
(11.61)\end{array}$ & $\begin{array}{c}-0.0142 \\
(-0.27)\end{array}$ & $\begin{array}{c}0.2147^{*} \\
(2.98)\end{array}$ & $\begin{array}{c}0.1977^{*} \\
(2.60)\end{array}$ & $\begin{array}{c}0.0283 \\
(0.25)\end{array}$ & $\begin{array}{c}0.0639 \\
(0.61)\end{array}$ \\
\hline$\alpha_{8}$ & $\alpha_{9}$ & $\alpha_{10}$ & $\alpha_{11}$ & & & & \\
\hline $0.0373^{*}$ & 0.0117 & -0.0011 & -0.0009 & & & & \\
\hline$(2.79)$ & $(0.88)$ & $(-0.19)$ & $(-0.13)$ & & & & \\
\hline \multicolumn{8}{|c|}{ Variance equation: } \\
\hline$\beta_{0}$ & $\beta_{1}$ & $\beta_{2}$ & & & & & \\
\hline $0.0001^{*}$ & $0.0885^{*}$ & $0.8937^{*}$ & & & & & \\
\hline$(3.32)$ & $(6.24)$ & $(54.89)$ & & & & & \\
\hline
\end{tabular}

The numbers in parentheses are t-statistics computed from the information matrix. Single * indicates significance at $1 \%$ level and double * indicates significance at 5\% level and triple * indicates significance at $10 \%$ level.

From Table 1 we observe that six coefficients are significant. In terms of our hypothesis, $\alpha_{2}$ is significant and indicates that increases in the price of gold also increase the price of oil. More specifically a $\$ 1$ increase in the price of gold explains $\$ 0.6$ increase in the price of oil over the sample period. However, the coefficients for both the current and one period lagged Euros are not significant.

The residual analysis from this regression equation shows no serial correlations, but the CUSUM-square test shows instability in variance and/or parameters. Although the GARCH variance captures the time varying nature of conditional variance, it cannot address if there is structural discontinuity in the level of variance.

In order to explore more effectively the causes for high oil prices over the sample period and its subsequent decline we investigate the following relationship subject to a three state Markov chain. The relationship of interest is: 


$$
\begin{aligned}
\Delta \text { Oil }_{\mathrm{t}}= & \alpha_{0, \mathrm{~S}_{\mathrm{t}}}+\alpha_{1, \mathrm{~S}_{\mathrm{t}}} \Delta \operatorname{Oill}_{\mathrm{t}-1}+\alpha_{2, \mathrm{~S}_{\mathrm{t}}} \Delta \operatorname{Gold}_{\mathrm{t}}+\alpha_{3, \mathrm{~S}_{\mathrm{t}}} \Delta \operatorname{Gold}_{\mathrm{t}-1}+\alpha_{4, \mathrm{~S}_{\mathrm{t}}} \Delta \mathrm{SP}_{\mathrm{t}}+\alpha_{5, \mathrm{~S}_{\mathrm{t}}} \Delta \mathrm{SP}_{\mathrm{t}-1}+ \\
& \alpha_{6, \mathrm{~S}_{\mathrm{t}}} \Delta \operatorname{Euro}_{\mathrm{t}}+\alpha_{7, \mathrm{~S}_{\mathrm{t}}} \Delta \operatorname{Euro}_{\mathrm{t}-1}+\alpha_{8, \mathrm{~S}_{\mathrm{t}}} \Delta \operatorname{Vix}_{\mathrm{t}}+\alpha_{9, \mathrm{~S}_{\mathrm{t}}} \Delta \operatorname{Vix}_{\mathrm{t}-1}+ \\
& \alpha_{10, \mathrm{~S}_{\mathrm{t}}} \Delta \operatorname{Ted}_{\mathrm{t}}+\alpha_{11, \mathrm{~S}_{\mathrm{t}}} \Delta \operatorname{Ted}_{\mathrm{t}-1}+\varepsilon_{\mathrm{t}, \mathrm{S}_{\mathrm{t}}}
\end{aligned}
$$

The subscript $S_{t}$ is used to denote dependence of these parameters on the prevailing Markov state. The law guiding the evolution of this unobserved state variable is a time homogenous transition probability matrix. The residual term is also dependent on the Markov state occurring and the variance of this residual variable is also state dependent. In fact, the realization of the residual variance is one way of classifying the states to which we may be able to attach economic significance.

\section{Analysis of Results}

Having remarked that regressions of the form in equation (1) are limited as a methodological tool, we now interpret the results of Tables 2 and 3. In Table 2 we obtain 3-regimes of low, average and high volatility. It is worth highlighting that the low and average volatility regimes are quite similar each having variance 3.15 and 4.09 units (log price difference of oil), respectively. These variances are those of the error terms $\left(\varepsilon_{t, S_{t}}\right)$ as in equation (3). However, the high volatility regime is very high at 22.5 units and captures the period of crashing oil prices. The duration in days of regimes 1,2 and 3 are respectively 323.62, 62.75 and 52.96. These numbers do not allow us to distinguish neatly before and after the crisis but instead offer us three very distinguished regimes identified in Figure 1. The financial crisis regime is identified as the period of September 2008 to mid April 2009. Although the crisis started during August 2007, the truly turbulent period is that identified in the bottom panel of Figure 1.

Table 2 confirms that during the low volatility regime identified as $S_{t}=1$, only one variable is significant, namely contemporaneous price changes in gold. All the remaining 11 variables fail to be significant. We can conclude that during a very low volatility regime, the price of oil is determined by the fundamentals of global supply and demand. This global demand is determined by the growth of global income since the 
demand for oil is inelastic. With respect to the global supply of oil, the oil cartel has encouraged global supply to grow by the rate of increase of the global income so that average prices remain stable. Obviously, these fundamentals are affected by frequent shocks in both the supply and demand, mostly supply interruptions. Furthermore, the relative value of the dollar is captured by changes in the price of gold that in turn determines the price of oil.

During the second regime that has a slightly higher volatility, oil prices are impacted by changes in the price of oil lagged, and also both gold and the Euro are now significant. In addition we also obtain significance for the S\&P500 Index, VIX and Ted. When volatility increases dramatically, gold, the Euro, S\&P 500 and Ted become significant explanatory variables. These results support our hypothesis that different factors explain the movement in the price of oil across regimes of increasing volatility. Specifically, fundamentals explain the price during stable volatility, while gold and the Euro both contemporaneously and in one lag explain oil prices changes during higher volatilities.

Since Table 2 indicates that regimes 1 and 2 have very similar variances of 3.15 and 4.09, we re-estimate the model in equation (3) with only two regimes. The results are presented in Table 3. Observe now that regime 1 has a variance of 3.4107 which as expected is between 3.15 and 4.09 and this regime now lasts on average about 595.34 days. The second regime has a variance of 21.9958 which is about 7 times higher. The results of Tables 2 and 3 are similar. Specifically in Table 3 and in the new regime 1 (that now represents both the low and medium volatility regimes of Table 2), gold (as before) and also the Euro lagged are the two significant explanatory variables. In the high variance regime (that captures the financial crisis from mid September 2008 to mid April 2009) gold, oil and the S\&P500 Index, all contemporaneously and with a one period lag are significant along with $\Delta \operatorname{Vix}(\mathrm{t})$. These results also support our hypothesis that the financial crisis had a great impact in the crashing of the oil prices. 


\section{Table 2}

Oil Price Dynamic: Three State Markov Chain Paradigm

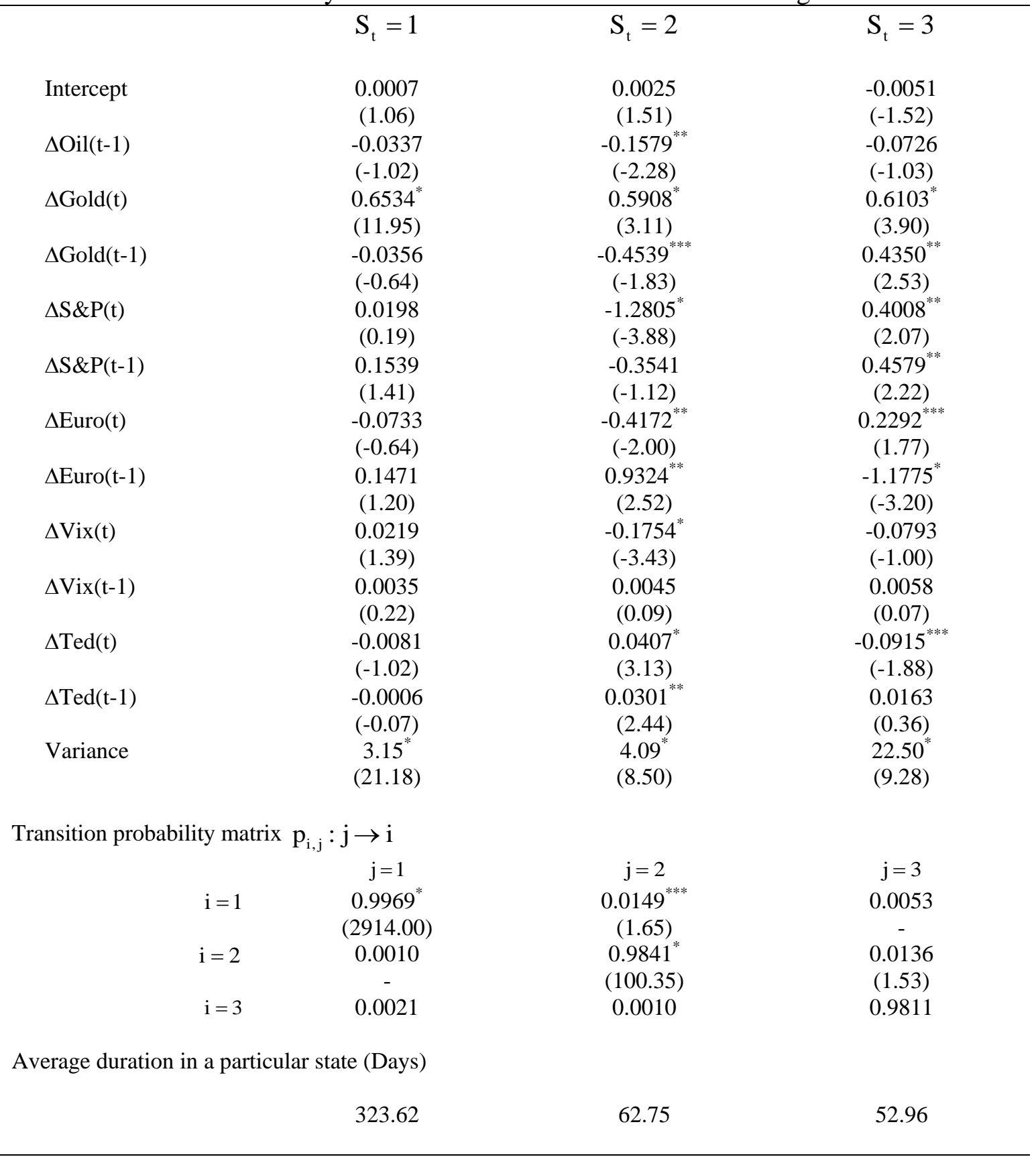

The numbers in parentheses are t-statistics computed from the information matrix. Single $*$ indicates significance at $1 \%$ level and double * indicates significance at $5 \%$ level and triple * indicates significance at $10 \%$ level. 
Table 3

Oil Price Dynamic: Two State Markov Chain Paradigm

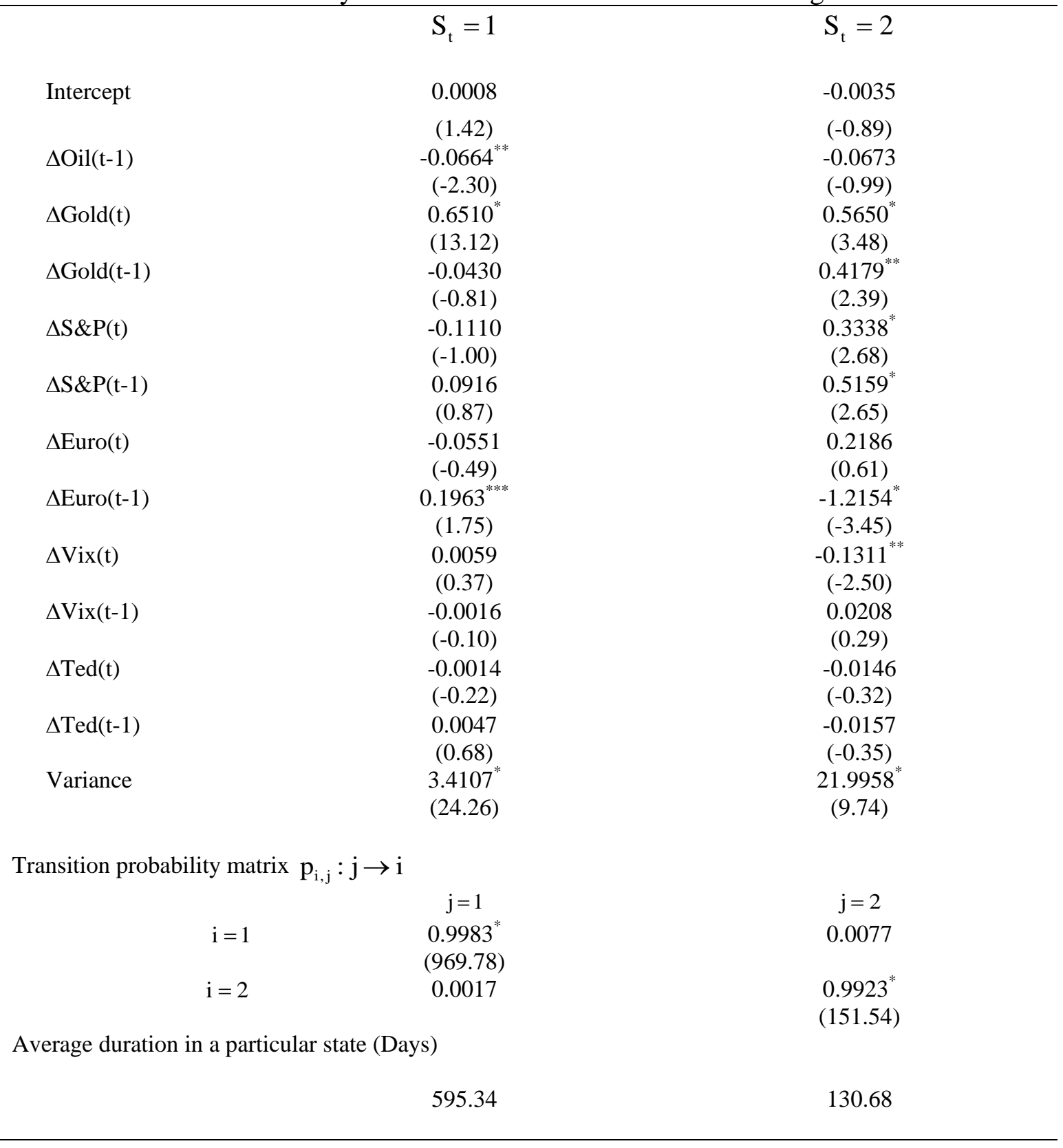

The numbers in parentheses are t-statistics computed from the information matrix. Single $*$ indicates significance at $1 \%$ level and double * indicates significance at $5 \%$ level and triple * indicates significance at $10 \%$ level. 
Figure 1

Oil Price Dynamic: Probability of Three Markov States Over the Sample Period
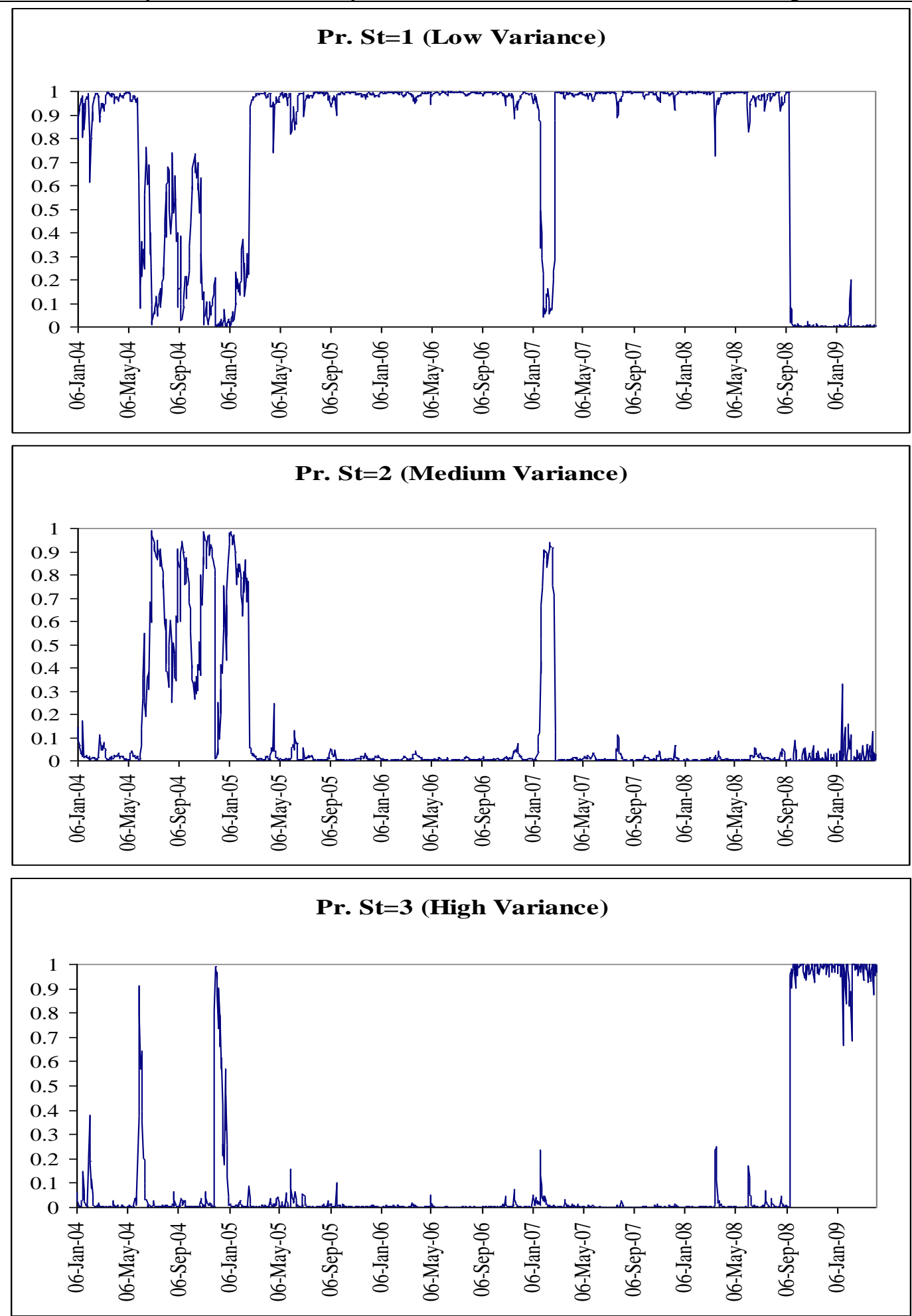
Figure 2

Oil Price Dynamic: Probability of Two Markov States Over the Sample Period
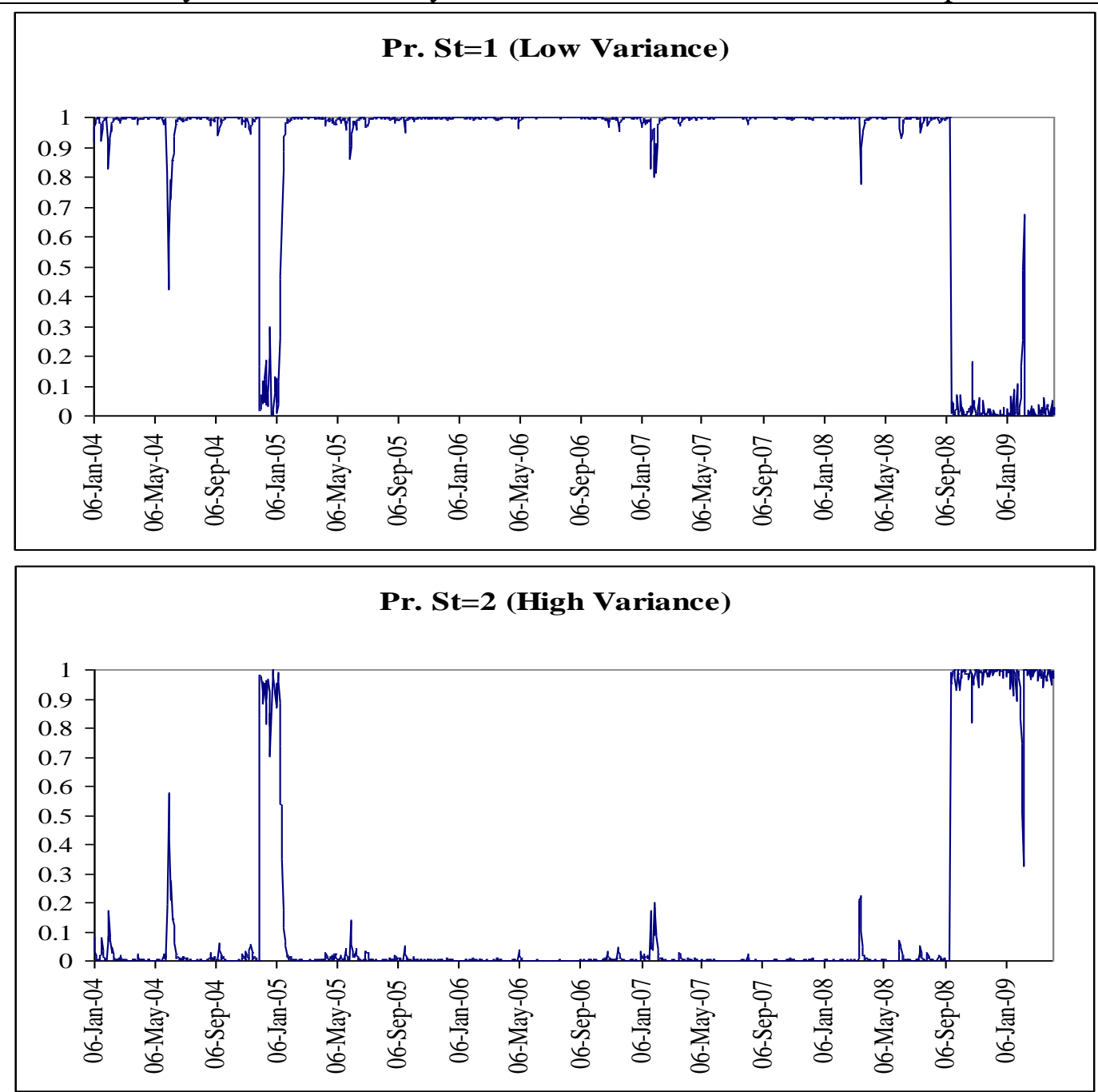


\begin{tabular}{cccccc}
\hline \multicolumn{7}{c}{ Table 4} \\
Logit Model Results & (Coefficient & $\alpha_{1}$ for Different Explanatory Variables) \\
\hline$\Delta$ Oil(t-1) & $\Delta$ Gold(t-1) & $\Delta$ S\&P(t-1) & $\Delta$ Euro(t-1) & $\Delta$ Vix(t-1) & $\Delta$ Ted(t-1) \\
962.31 & 1279.34 & 3434.46 & 9571.55 & 20.57 & -4.12 \\
$(10.24)$ & $(4.45)$ & $(8.99)$ & $(8.75)$ & $(1.62)$ & $(-0.82)$ \\
{$[0.25]$} & {$[0.06]$} & {$[0.27]$} & {$[0.13]$} & {$[0.01]$} & {$[0.01]$} \\
\hline
\end{tabular}

These results are obtained from EViews using Binary estimation method. Numbers in parentheses are tstatistics and in square brackets are pseudo R-square.

\section{Model comparison}

In order to understand the efficacy of our regime based approach we carry out model comparisons in a consistent framework. We have already indicated that the CUSUM square test of the residuals from the linear regression model points to structural breaks in variance and/or parameters of the model. Regime switching model is a straightforward way to address that issue. Heteroskedasticity in the system is addressed by allowing unconditional variances to change between regimes and the discontinuity in the parameters are addressed by having regime dependencies. In order to understand the underlying dynamics and the number of regimes to be incorporated, we estimate models with two regimes and three regimes. We, however, need a mechanism to distinguish between these two models. Allowing more regimes increases the number of model parameters almost exponentially and it becomes computationally intractable. However, before discussing the model comparison results we give a brief review of the consistent methodology we employ.

The issue of comparing models has been a long standing one in econometrics and statistical science. Dealing with nested models is now almost trivial as the log-likelihood can easily be compared using a simple likelihood ratio test. However, comparing nonnested models as well as models incorporating regimes is a different matter. Various measures of in sample fit, mostly non-parametric, have been advocated for some time. 
These measures, designed for comparing predictions, are inconsistent and unreliable at best. The most satisfactory gauge of model fit is the objective function, the log-likelihood and comparing the likelihood functions of two competing models will provide a definitive statement regarding the superiority of one over the other. Vuong (1989) developed such a measure. The test proposed by Vuong is simple in its approach and estimation only requires that all the conditional densities computed at the point of convergence during the optimization process be stored. The basic idea of constructing this test is given in the appendix.

The classical likelihood ratio based test deals with models that are nested where, by constraining some of the parameters of one model, the second model is obtained. In our case, the models with two and three regimes are clearly non-nested. Vuong (1989) defines these concepts of nesting in terms of spanning of the conditional densities and developing the asymptotic distribution of the test statistics.

Although, the use of Vuong's non-nested likelihood ratio test is a relatively recent development in financial economics, it has been successfully adopted by, Danielsson (1998), Ball and Torous (1999) and Smith (2002) to name a few. This test statistic has a well-defined limiting distribution; i.e. $\mathrm{N}(0,1)$. If the statistic is greater than the critical value at the 5\% level then the Markov switching model captures the data generating process better than the other model. Similarly, Vuong demonstrate that the nested model test using his approach turns out to be same as in classical test and has the Chi-square limiting distribution.

In our study, Vuong's test statistic comparing the three and the two regime models turns out to be 2.21 and the $5 \%$ level critical value of the distribution is 1.64 . It, therefore, shows that the three regime model is better at capturing the influence of the explanatory variables on the oil price changes over the sample period.

\section{Driver of regime changes}

We have already noticed that the volatility of the Markov switching model residuals is instrumental to the regime classification of the data and demonstrate the importance of regimes how the explanatory variables react. Regime 3 (in the three regime model) has 
much greater variance compared to the other regimes. The probability plots of different regimes in Figures 1 and 2 do correspond to some of the known historical events.

Focusing on the high variance state in the three regime model, the two peaks in the initial part of the sample corresponds to $2^{\text {nd }}$ June 2004 and $7^{\text {th }}$ December 2004. After this the probability of being in the high variance state is very small until September $15^{\text {th }}$ 2008. From then on, until the end of the sample in April 2009, the oil price change remains in the high variance state. This directly corresponds to the global financial crisis period.

Thus, it is reasonable to enquire whether the explanatory variables have power to influence the oil price change to move in and out of a regime. In order to quantify this we estimate a Logit regression model of the form:

$$
\mathrm{p}_{\mathrm{t}}=\frac{1}{1+\exp \left(-\alpha_{0}-\alpha_{1} \mathrm{x}_{\mathrm{t}-1}\right)}
$$

where $p_{t}$ denotes the filtered probability of being in the high volatility regime at time $t$, $\alpha_{0}$ and $\alpha_{1}$ are regression coefficients and $x_{t}$ is the squared explanatory variables as shown in Table 4. This list is same as our model explanatory variables.

Table 4 gives the results of estimating the Logit model as described above. The signs and significance of the coefficients representing the: lagged oil price changes, lagged gold price changes, lagged stock market returns, and lagged Dollar price of Euro changes are all very important in causing regime movement. In other words, a large jump in these variables up or down may indeed be followed by a regime shift. On the other hand, VIX and TED are not able to influence such regime movements. One reason this occurs is that TED and VIX remained elevated while the price of oil crashed along with the strengthening of the U.S. dollar and the crashing of the S\&P 500 Index. Oil experienced relatively small corrections. 


\section{Conclusions}

We use daily data of 1327 observations from January 2004 to April 2009 to find explanatory variables for the behavior of oil prices. This period includes sub-periods of very stable oil prices, rapidly increasing prices and then the crash that occurred during the middle of the financial crisis and more specifically during the second half of 2008 . We claim that the traditional methodology of regression analysis is not appropriate during this turbulent period and propose instead a Markov switching regime methodology that optimally selects regimes of similar variance and estimates the models in these regimes by identifying the varying significance of the independent variables considered.

Having observed the dramatic increase of oil prices during sub-periods of our sample, we hypothesize that different factors explain the behavior of oil prices across different regimes. First, during a low oil price volatility regime it is reasonable to argue that fundamentals described by global supply and demand for oil drive prices. These fundamental factors initially contributed to small increases in the price of oil on the grounds that a rise in global demand, particularly the demand from China and India was taking place. Concurrently some disruptions in the supply of oil were occurring. However, when the increases in the price of oil escalated, analysts recognized that additional factors were needed to explain such dramatic changes.

We propose in this paper that the decline in the value of the U.S. dollar, measured both by the appreciation of the Euro and of gold prices, played an important role as oil suppliers demanded compensation for the declining value of the dollar. We also claim that a euphoric stock market represented by the S\&P 500 Index had an impact on oil prices. Using a Markov switching regime methodology we find evidence that this hypothesis is true prior to the financial crisis, but its validity does not hold after the crisis when oil prices crashed along with the S\&P500 Index, the dollar rallied as a safe haven and the price of gold corrected mildly. 


\section{References:}

Ball, C. and Torous, W. N. (1999), The Stochastic Volatility of Short-term Interest Rates: Some International Evidence, Journal of Finance, 56, pp. 2339-2359.

Ciner, C., (2001), On the Long-run Relationship between Gold and Silver: A Note, Global Financial Journal, 12, pp. 299-303.

Danielsson, J. (1998), Multivariate Stochastic Volatility Models: Estimation and a Comparison with VGARCH Models, Journal of Empirical Finance, 5, pp. 155173

Hamilton, J. (2009), Causes and Consequences of the Oil Shock of 2007-08, National Bureau of Economic Research Working Paper \# 15002.

Hammoudeh, S., Sari, R., and Ewing, B.T., (2009), Relationship Among Strategic Commodities and With Financial Variables: A New Look, Contemporary Economic Policy, 27 (2), pp. 251-264.

Krichene, N., (2007), Recent Dynamics of Crude Oil Prices, IMF Working Paper No. $06 / 299$.

Smith, D. (2002), Markov-Switching and Stochastic Volatility Diffusion Models of Short-Term Interest Rates, Journal of Business and Economic Statistics 20, pp. 183-197.

Vuong, Q. H. (1989), Likelihood Ratio Test for Model Selection and Non-Nested Hypotheses, Econometrica 57, 307-333. 


\section{Appendix:}

Vuong's (1989) test for selection of non-nested models is related to the classical likelihood ratio based test and uses Kullback-Leibler Information criterion to measure the closeness of the model to the true data generating process. The test is directional and may be used to decide which model is performing better than the other one in explaining the data under consideration.

Consider two competing models with the conditional densities for the observations, $y$, with the explanatory variables, $\mathrm{z}$, are given by, $\mathrm{f}(\mathrm{y} \mid \mathrm{z} ; \Theta)$, and $\mathrm{g}(\mathrm{y} \mid \mathrm{z} ; \Psi)$, where $\Theta$ and $\Psi$ are the parameter vectors for the first and second model respectively. For non-nested models, under certain regulatory conditions, Vuong showed that the following test statistic,

$$
\frac{\sum_{\mathrm{i}=1}^{\mathrm{n}} \ln \mathrm{f}\left(\mathrm{y}_{\mathrm{i}}\right)-\ln \mathrm{g}\left(\mathrm{y}_{\mathrm{i}}\right)}{\sqrt{\mathrm{n}} \hat{\omega}_{\mathrm{n}}} \stackrel{\mathrm{D}}{\longrightarrow} \mathrm{N}(0,1)
$$

where $\mathrm{n}$ is the number of observations and $\widehat{\omega}_{\mathrm{n}}$ is given by,

$$
\widehat{\omega}_{\mathrm{n}}^{2}=\frac{1}{\mathrm{n}} \sum_{\mathrm{i}=1}^{\mathrm{n}}\left[\ln \mathrm{f}\left(\mathrm{y}_{\mathrm{i}}\right)-\ln \mathrm{g}\left(\mathrm{y}_{\mathrm{i}}\right)\right]^{2}-\left[\frac{1}{\mathrm{n}} \sum_{\mathrm{i}=1}^{\mathrm{n}}\left[\ln \mathrm{f}\left(\mathrm{y}_{\mathrm{i}}\right)-\ln \mathrm{g}\left(\mathrm{y}_{\mathrm{i}}\right)\right]\right]^{2}
$$

is the variance of the test statistic.

This statistic is easy to compute once the maximum likelihood estimation of the parameters has been carried out. The procedure needs to store all the conditional densities computed at the point of convergence. If the computed test statistic is higher than the chosen critical value we reject the hypothesis that the models are equivalent in favor of the model represented by the conditional densities, $\mathrm{f}(\mathrm{y} \mid \mathrm{z} ; \Theta)$ 